\title{
South China Sea Wave Height Trends Analysis Using 20CR Reanalysis
}

\author{
Lingli $\mathrm{Wu}^{1,2}$ \\ ${ }^{1}$ Jiangsu Key Laboratory of Coast Ocean Resources \\ Development and Environment Security, \\ Hohai University, \\ Nanjing, China. \\ ${ }^{2}$ State Key Laboratory of Satellite Ocean Environment \\ Dynamics(Second Institute of Oceanography, SOA) \\ Hangzhou, China \\ lingliwu036@163.com
}

\author{
Xing Li \\ Fishery Engineering Research Institute of \\ Chinese Academy of Fishery Sciences, \\ Beijing, China
}

\author{
Teng $\mathrm{Wu}$ \\ ${ }^{1}$ Jiangsu Key Laboratory of Coast Ocean Resources Development and Environment Security, \\ Hohai University, \\ Nanjing, China.
}

\begin{abstract}
This study investigates long-term significant wave heights trends in the South China Sea. The Hs-SLP relationship in each domain is represented by a multivariate regression model with lagged dependent variable, which is calibrated and validated using the ERA-Interim reanalysis of Hs and SLP for the period 1981-2010. The 6-hourly Hs time series at each grid point was homogenized for discontinuities identified in the regional mean series. The homogenized wave heights were then used to assess wave height trends over the period 1911-2010. For comparison, the wave height trends derived from the inhomogenized wave heights were also showed. The reconstructed wave heights trends are also compared with the trends as derived from ERA40 dynamical wave reanalysis datasets.
\end{abstract}

Keywords-South China Sea; wave height trend; statistical downscaling; Mann-Kendall test

\section{INTRODUCTION}

Under the circumstance of climate warming[3], the globally mean sea level has risen over the $20^{\text {th }}$ Century [11], and the change of ocean wave height is also affected[14]. Thus wave height modeling is of great importance since increased wave heights on top of the rising sea level could not only increase the risk of coastal flooding, but also impact the offshore industries.

There are two approaches to project ocean wave heights: dynamical downscaling and statistical downscaling. Dynamical downscaling involve using climate-model-simulated atmospheric variables to drive an ocean wave model while statistical downscaling relies on statistical relationships between selected large scale predictors and regional scale predictands $[3,8,9]$. Since dynamical approach was found to be not as good as the statistical methods in terms of reproducing the observed climate and interannual variability of the predictand, several works were done with statistical downscaling $[7,14,15]$. The general principle is to establish a link between the simulated large scale and the finer scale of extreme events using one or a combination of statistical models calibrated on observational datasets.

Observations of ocean wave heights are available only for the last few decades at limited buoy locations around the globe, in addition to some volunteer ship observations which are limited to major ship routes. Satellite data for wind speed and wave height have global coverage; however, they span only the last couple of decades, which hampers reliability of trend estimates, especially for extremes [17]. And until recently, reanalysis of the atmosphere were limited to span only the second half of the 20th century. The 20th century reanalysis (20CR) [1] is the first reanalysis data set that spans over the past 140 years (1871-2010). Thus, this data set makes it possible to assess South China sea wave height trends on a centennial scale, which would be helpful for related decision making.

South China Sea (SCS) is China's deepest and largest sea and it is the world's third continental marginal sea (second only to the Coral Sea and the Arabian Sea). Surrounded by most of the peninsula and the islands, SCS is the major shipping channel between South Pacific and the Indian. SCS is also an important natural resource of oil and gas production, tourism and recreation, commerce, navigation and fisheries [12]. However, the information on potential long-term changes of wave height in the SCS is fragmented and incomplete. The number of studies on SCS waves covers only a short period of time $[5,10]$. This study aims to make wave height trends assessment on a centennial scale on SCS by a statistical reconstruction of historical wave heights using the mean sea level pressure (SLP) fields of the 20CR ensemble.

The rest of this article is structured as following: The data sets and methodologies used in this study are described in Sections 2. Section 3 presents the two series of wave height 
climate which derived from the 20CR reconstructed wave height series before and after homogenization, in comparison concluding remarks are given in Section 5.with that derived from ERA40 and ERA-Interim wave reanalysis data sets. Historical wave height trends derived from 20CR are described in Section 4. Finally the results and some concluding remarks are given in Section 5.

\section{DATA AND METHODOlOGY}

\section{A. Data}

We use the ERA-Interim Reanalysis [2] of the atmosphere (SLP) and ocean significant wave heights $\left(H_{s}\right)$ for the period 1981-2010 to calibrate and validate the statistical relationship between the predictand $H_{s}$ and its SLP-based predictors[15]. The model calibration period is from 1981 to 2000 and the evaluation period is from 2001 to 2010 . Using the best chosen model (with the best set of predictors) in Wang's research, we also use the 30-yr (1981-2010) data from the ERA-Interim Reanalysis to recalibrate the best model, which is then used to reconstruct $H_{s}$. Then, the 20CR ensemble of SLP fields for the period 1871-2010 [1] are used to derive time series of the predictors to reconstruct the corresponding significant wave heights $\left(H_{s}\right)$ in the SCS. Since the 20CR ensemble of SLP fields are available on a $2^{\circ}-$ by- $2^{\circ}$ lat/long grid, this study uses the ERA-Interim SLP data on this grid, and the $H_{s}$ data, on a $1^{\circ}$-by $-1^{\circ}$ lat/long grid. All the SLP and $H_{s}$ data are 6-hourly instantaneous values. The unit is $\mathrm{hPa}$ for SLP and $\mathrm{m}$ for $H_{s}$.

To find out the seasonal difference of ocean wave height variations, we model the 6-hourly $H_{s}$ in four seasons: JFM (January-February-March), AMJ (April-May-June), JAS (JulyAugust-September), and OND (October-November-December). And JFM refers to winter and JAS refers to summer in this paper.

\section{B. Wave modeling method}

We use the multivariate regression model of the form[Wang et al., 2012]:

$$
H_{t}=a+\sum_{k=1}^{K} b_{k} X_{k, t}+\sum_{p=1}^{P} c_{p} H_{t-p}+u_{t}
$$

where $H_{t}$ is the Box-Cox transformed $H_{s}$ at a target wave grid point, $X_{k, t}$ are the $K$ SLP-based predictors that are retained for the wave grid point, $P$ is the order of lags of the predictand, and the residuals $u_{t}$ can generally be modeled as an $M$-order autoregressive process, $\mathrm{AR}(\mathrm{M}) . u_{t}$ is a white noise process if $M$
$=0$. And the detailed reason of the selection of model and predictors is described in [15]. The main difference of the model used in this article is that the predictor is based on semienclosed regional scale while Wang's is based on global scale.

Due to different wave surge influence to Sea level pressure (SLP) based predictor according to different SLP field choosing, the same model may have different projection performance. So the first thing is to select a suitable SLP field, the predictor domain (PD) to make the projection. We calculated the model performance to compare PD1 and PD2. Also we added the global scale projection result (W14) of Wang et al. (2012) to make sure whether the regional scale predictor performs better than that based on global model. Since the model skill with the PD2 got the best results, PD2 was chose to make the $H_{s}$ reconstructions.

We compare the model performance mainly by the hit rate (HR) and root mean square errors (RMSEs).For the hit rate (HR) shown in Fig. 1, a hit is defined as when the forecast value and the corresponding observed value fall within the same category. We used the 5 th, $10^{\text {th }} \ldots$, and 95 th percentiles of the observed values to define 20 categories for calculating the hit rates to assess the model skill in predicting $\mathrm{Hs}$ in each category. A hit rate is the ratio of the number of hits to the number of observations in the category.

The relative RMSE is the RMSE expressed in percentage of the corresponding 2001-2010 mean $\mathrm{H}_{\text {s }}$ (i.e., the mean of the validation period). The RMSEs are defined as

$$
R M S E=\sqrt{\frac{1}{N} \sum_{t=1}^{N}\left(H_{s}(t)-\hat{H}_{s}(t)\right)^{2}}
$$

The four grid points chosen in the South China Sea are: $\left(9^{\circ} \mathrm{N}, 107^{\circ} \mathrm{E}\right)\left(\right.$ South Vietnam coast), $\left(11^{\circ} \mathrm{N}, 114^{\circ} \mathrm{E}\right)$ (central SCS), $\left(20^{\circ} \mathrm{N}, 112^{\circ}\right.$ E) (East of Hainan Island) and $\left(25^{\circ} \mathrm{N}, 120^{\circ} \mathrm{E}\right)$ (Taiwan Strait). We could see that the model skill is higher in the cold seasons (winter and fall) than in the warm seasons (summer and spring), which is also true in the global setting of Wang et al. [2014] as represented by the parameter W14, as shown in Fig. 2. W14 stands for the result of the global predictor domain of Wang et al. [2014]. We could find that the improvement of our regional model settings over the global model setting is noticeable. 
(a) Performance for modelling winter $\mathrm{Hs}$



\section{(b) Performance for modelling summer $\mathrm{Hs}$}
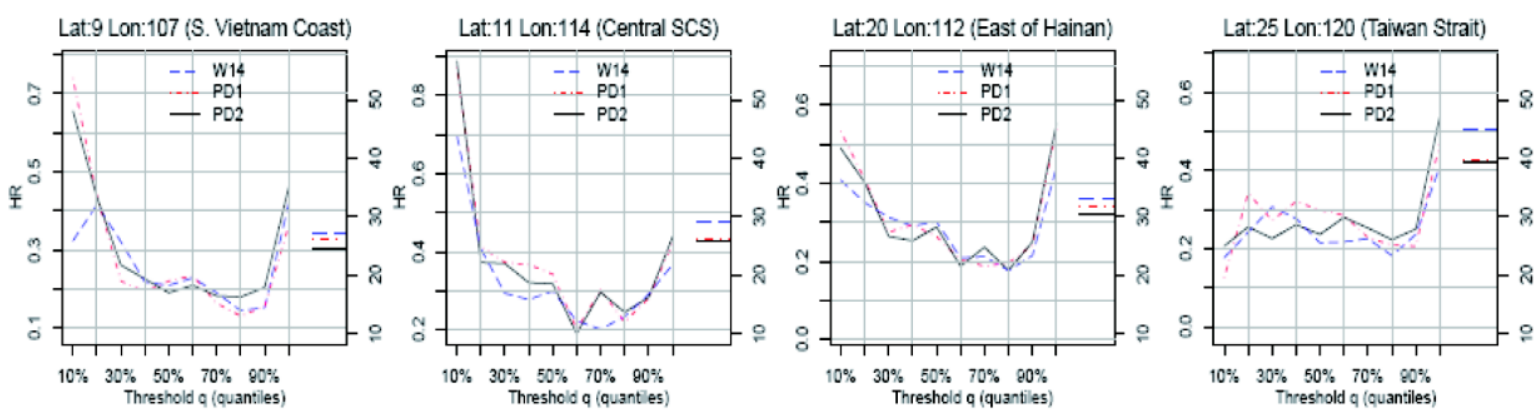

Fig. 1. The HR(see the left vertical axis) and RMSE(see the right vertical axis) of the model with the indicated predictor-domains (PD1 and PD2) for winter (JFM) and summer (JAS) significant wave heights $(\mathrm{Hs})$ at eight different grid points in SCS.

(a) Use PD2 for South China Sea (SCS)

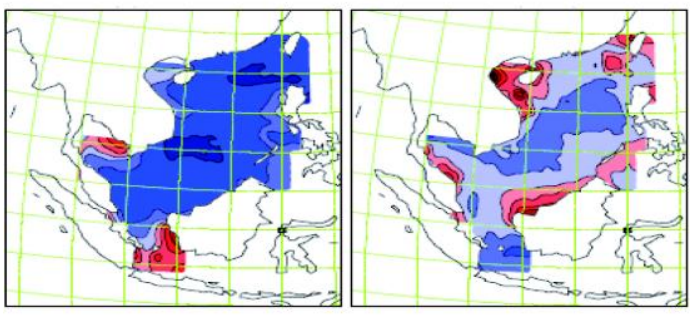

(b) Use W14 for South China Sea (SCS)

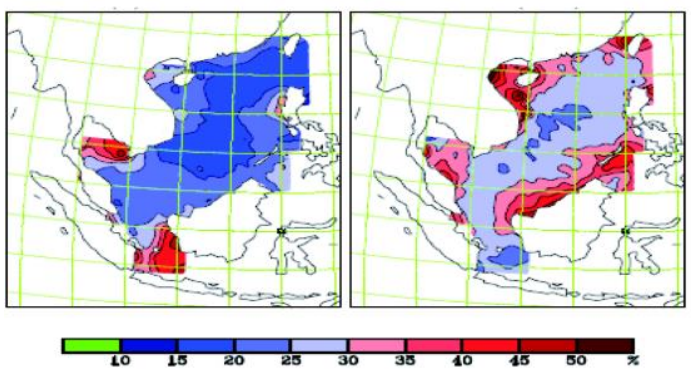

Fig. 2. The RMSE of the statistical model with Predictor Domain 2 (PD2) for the significant wave heights (Hs) in SCS in winter (JFM, left panels) and summer (JAS, right panels)

Having got the best skilled model of SCS with the corresponding best predictors derived with the PD2, we used the 30-year period data (1981-2010) of SLP and Hs from the ERA-Interim to recalibrate the best model which is also performed in Wang et al. [2012]. Then the recalibrated model was used to reconstruct the SCS significant wave height. Namely, the predictors were derived from each part of the 20CR ensemble of 6 hourly SLP and then were fed to the calibrated best model to hindcast Hs at 6 hourly time scale.

\section{RECONSTRUCTED WAVE HeIGHT SERIES COMPARISON(BEFORE AND AFTER HOMOGENIZATION)}

Fig. 3 shows the climatological mean fields of annual mean (Havg) and annual maximum (Hmax) significant wave heights in the South China Sea (SCS) as derived from the reconstructed 20CR ensemble-mean $\mathrm{Hs}$ and derived from the ERA40 dynamical wave reanalysis before homogenization.
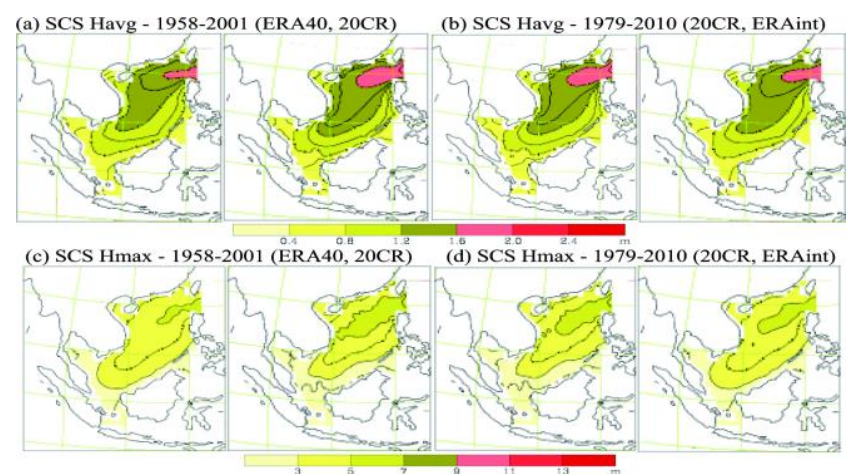

Fig. 3. The Havg and Hmax significant wave heights in the SCS, as derived from the 20CR ensemble mean, the ERA40 and ERA-Interim dynamical wave reanalysis before homogenization. 
As Wang et al. [2013] has described that the 20CR data may have partial inhomogeneities in the early decades due to the very low amount and intensity of observations available for assimilation. Following Wang's method, we detected the sudden changes and completed the homogenization process.


Fig. 4. The Havg and Hmax significant wave heights in SCS, as derived from the 20CR ensemble mean, the ERA40 and ERA-Interim dynamical wave reanalysis after homogenization.

Fig.4 shows the climatological mean fields of annual mean (Havg) and annual maximum (Hmax) significant wave heights in SCS as derived from the reconstructed 20CR ensemblemean $\mathrm{Hs}$ and derived from the ERA40 dynamical wave reanalysis after homogenization. Comparing with the results showed in Fig.3, the statistical reconstructions presented the annual mean and maximum wave height climates fairly well after homogenization (Fig. 4).

However, the reconstructions slightly overestimate the annual mean and maximum wave heights in SCS especially compared with ERA40 (Fig.4a and Fig.4c). This is partly because that the statistical reconstructions are derived from the ERA-Interim reanalysis, which has better resolution than the ERA40. Within the resolution scope of the ERA40 and ERAInterim models, significant wave heights especially extreme series are better reproduced with a higher resolution. This is evidently described by J.-R. Bidlot's comparison in ECMWF Report Series and also is presented in the results that the reconstructed annual wave height climate is more similar to its ERA-Interim counterpart than to its ERA40 counter part (compare Fig.4a and $4 \mathrm{c}$ with $4 \mathrm{~b}$ and $4 \mathrm{~d}$ ). Thus the ERA-Interim annual mean wave height climate largely determines the reconstructed annual mean wave height climate.

\section{Historical Wave Height TRENDS}

From the inhomogenized and homogenized 6 hourly significant wave heights, we picked up the annual and seasonal mean and maximum values of $\mathrm{Hs}$ at each grid point in SCS. We used the trend analysis method of Wang and Swail [2001] to assess trends in Hs time series which are not asymmetrically distributed. And this method is on the basis of Mann-Kendall test for trend against randomness [6] and an iterative procedure is applied to display the effect of lag-1 autocorrelation on trend analysis. This nonparametric method with no distributional assumption for the data is less sensitive to gross errors and has been found to have best performance comparing with other trend estimate methods [18]. So we choose to use this method on each sequence of Hs statistics at each grid point in South China Sea.
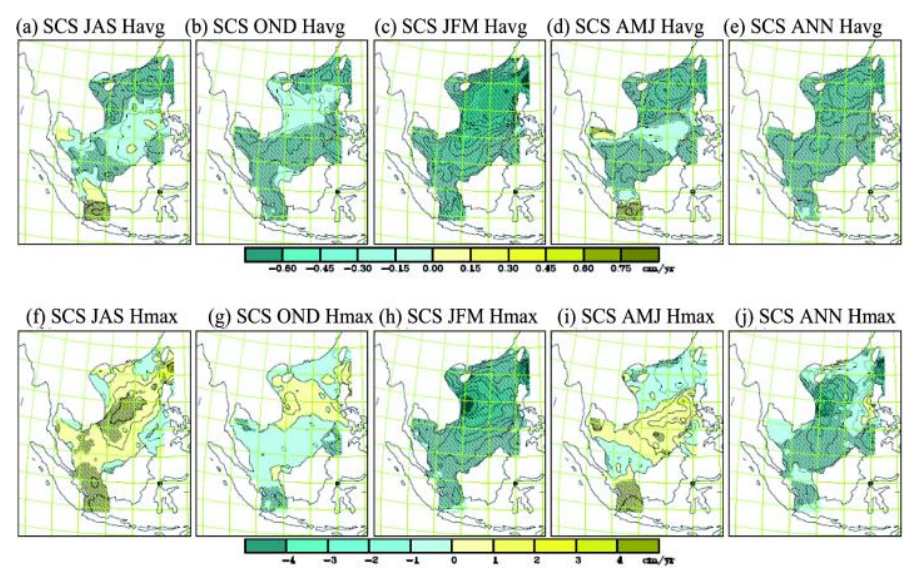

Fig. 5. Maps of monotonic trends estimated from the homogenized significant wave heights Hs in SCS.

Fig.5. shows the trend analysis results derived from homogenized 6 hourly Hs series in SCS compared with Fig. 6 which shows the results of inhomogenized series (Stippling denotes areas where the significant trends exceed 5\% level). For the inhomogenized series, the seasonal mean/maximum of significant wave heights only shows a significant decreasing trend mainly in JFM season (Fig. 6c and 6h).

Compared with Fig.6, it shows that homogeneities greatly improve the estimate of wave height trends. In SCS, as shown in Fig.5a-5e, the annual/seasonal mean of significant wave heights shows a significant decreasing trend over the period 1911-2010, with the decreases being largest and most extensively significant in winter, and least extensively significant in summer. However, the seasonal maximum of significant wave heights shows a significant increasing trend in central SCS in summer and spring (Fig. 5f, Fig.5i), and along the South Coast of China in summer (Fig. 5f). These increases were accompanied with a significant decreasing trend in winter maximum $\mathrm{H}_{\mathrm{s}}$ (Fig. 5h), and with little change in autumn (Fig. $5 \mathrm{~g}$ ). Trends in the annual maximum of significant wave heights in the South China Sea are predominantly negative, with the exception of the nearshore area along the South Coast of China where it seems to have increased over the past century (Fig. 5j).

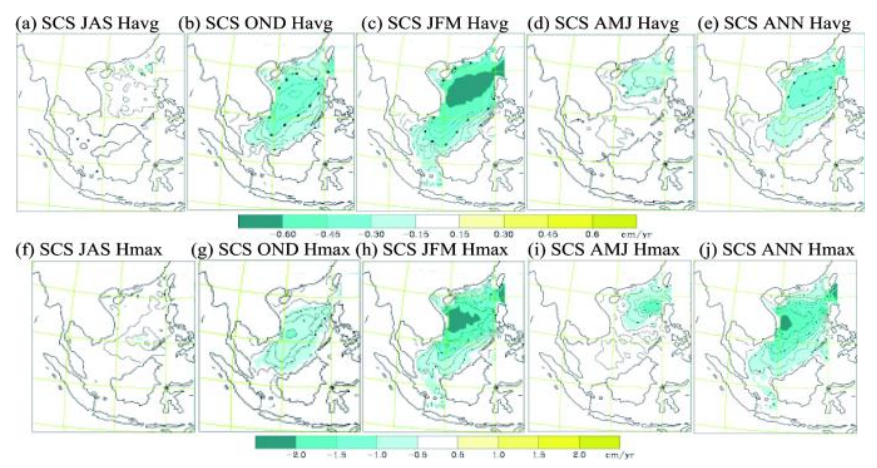

Fig. 6. Maps of monotonic trends estimated from the inhomogenized significant wave heights Hs in SCS. 


\section{CONCLUSIONS}

The 20CR ensemble of 6 hourly SLP fields and a multivariate regression model with lagged dependent variable to represent the $H_{s}$-SLP relationship at each grid point were used to reconstruct 6 hourly Hs in the SCS of the period from 1871 to 2010. We use the ERA-Interim data of Hs and SLP of the period 1981-2010 to calibrate and assess the multivariate regression model. The result demonstrate that our statistical reconstructions of 6 hourly Hs fairly well represented the seasonal mean and maximum Hs climates of SCS as displayed by the ERA40 and ERA-Interim reanalysis.

We have examined temporal homogeneity for the SCS mean series of the ensemble mean of the reconstructed consecutive monthly mean $\mathrm{Hs}$ and have homogenized the 6 hourly Hs time series for the period 1911-2010 at each grid point in SCS for the few discontinuities identified in the respective regional mean series of the ensemble mean of the reconstructed consecutive monthly mean Hs. Then we have derived seasonal mean and maximum $\mathrm{Hs}$ from the homogenized 6 hourly Hs data and have used a nonparametric trend analysis method to estimate historical trends of seasonal and annual mean and maximum Hs in South China Sea.

We also derived seasonal mean and maximum Hs from the inhomogenized 6 hourly Hs data and estimated historical trends for comparison. And could found that homogenization really greatly improve the Hs trend estimate in SCS, although it does not differ much in the climatological mean fields.

And for homogenized series, the trend analysis results show that the Hs trends calculated in the period 1911-2010 are mainly negative except that the seasonal maximum wave heights have apparently increased in spring and summer in central South China Sea. Since South China Sea is subject to a lot of tropical cyclone activity such as typhoon in spring and summer, the trend increases in seasonal maximum wave heights might demonstrate an increase in tropical cyclone activity in SCS. And these might increase the public awareness of coastal hazards in this area.

\section{ACKNOWLEDGMENT}

Supported by the National Natural Science Foundation of China (Grant No. 51409080), Open Fund of Jiangsu Key Laboratory of Coast Ocean Resources Development and Environment Security (Hohai University) ( Grant No.JSCE201507), Major State Basic Research Development Program of China (Grant No. SOED1505) and Open Fund of the Key Laboratory of Ocean Circulation and Waves, Chinese Academy of Sciences (Grant No.KLOCW1505). The lead author is also grateful to the Climate Research Division of Environment Canada for providing for hosting her research visit.

\section{REFERENCES}

[1] Compo, G. P., et al. (2011). "The twentieth century reanalysis project." Q. J. R. Meteorol. Soc., 137, 1 - 28, doi:10.1002/qj.776.

[2] Dee, D. P., et al. (2011) . “ The ERA-Interim reanalysis: Configuration and performance of the data assimilation system." $Q$. J. R. Meteorol. Soc.,137(656), 553 - 597, doi:10.1002/gj.828.

[3] Hemer, M. A., Y. Fan, N. Mori, A. Semedo, and X. L. Wang (2013a). "Projected changes wave climate from a multi-model ensemble." Nature Clim. Change, 3, 471 - 476, doi:10.1038/NCLIMATE1791.

[4] IPCC (2013), Summary for Policymakers, in Climate Change 2013: The Physical Science Basis. Contribution of Working Group I to the Fifth Assessment Report of the Intergovernmental Panel on Climate Change, edited by T. F. Stocker et al., pp. 3 - 29, Cambridge Univ. Press, Cambridge, U. K.

[5] Jiang LF, Zhang ZX, Qi. YQ. (2010) . " Simulations of SWAN and WAVEWATCH III in the Northern South China Sea." Proceedings of the International Offshore and Polar Engineering Conference, Vol.1, 213-220,

[6] Kendall M.G. (1955), Rank Correlation Methods. Charles Griffin, 196pp., Charles Griffin, London, U. K.

[7] Lazarus, S. M., S. T. Wilson, M. E. Splitt, and G. A. Zarillo (2013) . " Evaluation of a Wind-Wave System for Ensemble Tropical Cyclone Wave Forecasting. Part II: Waves." Weather and Forecasting, 28(2), 316-330.

[8] Mori, N., T. Yasuda, H. Mase, T. Tom, and Y. Oku (2010) . "Projection of extreme wave climate change under global warming." Hydrol. Res.Lett., 4, 15 - 19, doi:10.3178/HRL.4.15.

[9] Planton, S., M. Déqué, F. Chauvin, and L. Terray (2008) . “ Expected impacts of climate change on extreme climate events." Comptes Rendus Geoscience, 340(9-10), 564-574.

[10] Qi YQ, Zhang ZX, Shi P.(2010). "Extreme wind, wave and current in deep water of South China Sea." International Journal of Offshore and Polar Engineering, Vol.20 No.1, 18-23

[11] Rhein, M., et al. (2013), Observations: Ocean, in Climate Change 2013: The Physical Science Basis. Contribution of Working Group I to the Fifth Assessment Report of the Intergovernmental Panel on Climate Change, edited by T. F. Stocker et al., pp. 256 - 315, Cambridge Univ. Press, Cambridge, U. K

[12] Salahuddin, A., and S. Curtis (2011). "Climate extremes in malaysia and the equatorial south china sea."Global and Planetary Change, 78, 83-91.

[13] Wang, X. L. and V. R. Swail (2001). " Changes of Extreme Wave Heights in Northern Hemi- sphere Oceans and Related Atmospheric Circulation Regimes." J. Climate, 14(No.10), 2204-2221. DOI: 10.1175/1520-0442(2001)014<2204:COEWHI>2.0.CO;2.

[14] Wang, X. L., V. R. Swail, and A. Cox (2010) . "Dynamical versus statistical downscaling methods for ocean wave heights." INTERNATIONAL JOURNAL OF CLIMATOLOGY, 30(3), 317-332.

[15] Wang, X. L., Y. Feng, and V. R. Swail (2012) . "North Atlantic wave height trends as reconstructed from the 20th century reanalysis." Geophysical Research Letters, 39(18).

[16] Wang, X.L., Y. Feng, G. P. Compo, V. R. Swail, F. W. Zwiers, R. J. Allan, and P.D. Sardeshmukh (2013). "Trends and low frequency variability of extra-tropical cyclone activity in the ensemble of Twentieth Century Reanalysis." Clim. Dyn., 40 (11), 2775- 2800, doi:10.1007/s00382-012-1450-9.

[17] Young, I. R., J. Vinoth, S. Zieger, and A. V. Babanin (2012) "Investigation of trends in extreme value wave height and wind speed." J. Geophys.Res., 117, C00J06, doi:10.1029/2011JC007753.

[18] Zhang, X., and F. Zwiers (2004). "Comment on "Applicability of prewhitening to eliminate the influence of serial correlation on the Mann-Kendall test" by Sheng Yue and Chun Yuan Wang."Water Resourc. Res., 40, W03805. 